\title{
El uso de tecnologías digitales en la enseñanza de las matemáticas en la visión de los profesores de la escuela de campo
}

\author{
José Sávio Bicho1 \\ saviobicho@yahoo.com.br \\ https://orcid.org/0000-0001-7616-6961
}

${ }^{1}$ Universidade Federal do Sul e Sudeste do Pará (UNIFESSPA, Brasil)

Recibido: 30/05/2020 Aceptado: 06/07/2020

\begin{abstract}
Resumen
Este artículo presenta una investigación que tuvo como objetivo investigar los desafíos y las posibilidades de utilizar las tecnologías digitales en la enseñanza de las matemáticas a la vista de los maestros de las escuelas de campo. Los datos se obtuvieron a partir de una investigacion realizada con solicitudes de cuestionarios a ocho académicos del curso de Grado en Educación de Campo de una universidad federal de Brasil, durante el desarrollo de la asignatura "Informática en la enseñanza de las matemáticas". Según los puntos de vista de los docentes deste estudio, como las tecnologías con potencial para la enseñanza y el aprendizaje de las matemáticas en las escuelas de campo, sin embargo, todavía es precario en cuanto a la disponibilidad de recursos tecnológicos, es porque la escuela pública del el campo pasa por dificultades pedagógicas y contratiempos. Por lo tanto, se necesitan inversiones y políticas públicas para enfrentar desafíos políticos y pedagógicos qué escuelas de campo, maestros, estudiantes y otros agentes escolares son afectados.
\end{abstract}

Palabras clave: Tecnologías digitales; Educación del Campo; Enseñanza de las matemáticas.

\section{O uso de tecnologias digitais no ensino de matemática na visão de professores de escolas do campo}

\begin{abstract}
Resumo
Este artigo apresenta uma pesquisa que teve como objetivo investigar desafios e possibilidades do uso de tecnologias digitais no ensino de matemática na visão de professores de escolas do campo. Os dados foram obtidos a partir de uma pesquisa realizada com aplicação de questionários a oito acadêmicos do curso de Licenciatura em Educação do Campo de uma universidade pública federal brasileira, durante o desenvolvimento da disciplina Informática no Ensino da Matemática. De acordo com os pontos de vista dos professores que participaram deste estudo, as tecnologias têm potencialidades para o ensino e aprendizagem de matemática nas escolas do campo, todavia ainda há precariedade quanto a disponibilização de recursos tecnológicos, isto porque a escola pública do campo passa por dificuldades e contrariedades pedagógicas. Portanto, é necessário investimentos e políticas públicas para o enfrentamento dos desafios políticos e pedagógicos que as escolas do campo, os professores, os alunos e os demais agentes escolares são submetidos.
\end{abstract}

Palavras-chave: Tecnologias Digitais; Educação do Campo; Ensino de Matemática. 


\title{
The use of digital technologies in teaching mathematics in the view of rural school teachers
}

\begin{abstract}
This article presents a research that aimed to investigate challenges and possibilities of using digital technologies in the teaching of mathematics in the view of rural school teachers. The data were initiated from research carried out with questionnaire applications to eight students of the Degree in Education course at the Federal Federal University of Brazil, during the development of the subject Informatics in the Teaching of Mathematics. According to the points of view of teachers who study this study, as the technologies with potential for teaching and learning mathematics in rural schools, however, it is still precarious as regards the availability of technological resources, it is because the public school of the rural goes through pedagogical difficulties and setbacks. Therefore, investments and public policies are needed to face political and pedagogical challenges, such as rural schools, teachers, students and other school agents.
\end{abstract}

Keywords: Digital Technologies; Rural Education; Mathematics teaching.

\section{Introdução}

Ultimamente temos visto o rápido avanço tecnológico em todos os setores da sociedade, as transformações estão acontecendo rápida e dinamicamente, com mudanças constantes. Esse advento tem demandado outras formas de ensino, uma vez que as crianças e jovens do nosso tempo estão inseridas no contexto digital, portanto as escolas do campo e urbanas tem cada vez mais como proposta pedagógica a incorporação das tecnologias digitais nos processos de ensino e aprendizagem, uma vez que potencializam a comunicação, permitem diferentes linguagens na difusão do conhecimento e possibilitam que pessoas de diferentes lugares e tempos compartilhem suas produções e conhecimentos (Almeida, 2010).

Com isso, destacamos que as tecnologias têm influenciado a sociedade, na profissionalização, no meio acadêmico e nas escolas urbanas e do campo, pois atualmente temos outros meios de disponibilidade e acesso de informações mediados pelas tecnologias digitais. Dessa forma, estamos cada vez mais vivendo um processo de modernização científica, das relações pessoais, da sociedade como um todo e da educação. Embora ainda tenhamos problemáticas de dimensão política e pedagógica na Educação do Campo, como o fechamento de escolas e currículos "urbanocêntricos", denota-se potencial da utilização

\footnotetext{
${ }^{1} \mathrm{O}$ termo urbanocêntrico refere-se à replicação dos processos e modelos urbanos no campo/rural. O modelo escolar urbanocêntrico expressa a proposta bancária e tecnocrática, bem como tensiona os currículos, os
} 
das tecnologias digitais, haja vista o uso de computadores/notebooks e celulares por alunos e professores, e a existência de laboratórios de informática. Importante destacar que não estamos generalizando que todas os sujeitos, comunidades e escolas do campo possuem acesso a computador, internet e laboratórios, visto que não procede, pois, ao contrário, muitos e tantos ainda estão excluídos das políticas públicas de acesso aos meios de informação e conhecimentos. Todavia, colocamos em voga a possibilidade desse acesso no meio rural, em que perpassa as lógicas capitalistas e coloniais sobre o espaço do campo e a educação.

Outrossim, concebemos a necessidade de as escolas e os professores prepararem-se para um bom desempenho de suas funções nesse cenário, por meio da adequação estrutural e qualificação profissional, que acompanhe o avanço tecnológico. Para tanto, emerge e ratifica-se a necessidade de políticas públicas e governamentais para qualificação profissional e reparo estrutural para o trabalho pedagógico com as diferentes mídias digitais.

Neste artigo, destacamos o uso de tecnologias digitais no contexto do ensino e aprendizagem de Matemática, cujo foco está em apresentar ao leitor reflexões sobre a informática no ensino de Matemática em escolas do campo, permeando as potencialidades para a aquisição de conhecimentos na nossa atual sociedade. O trabalho investigativo foi realizado com a colaboração de acadêmicos do curso de Licenciatura em Educação do Campo da Universidade Federal do Sul e Sudeste do Pará (Unifesspa), em Marabá (Pará, Brasil), durante a disciplina Informática no Ensino da Matemática, os quais responderam a questionários o que possibilitou apreender as visões dos colaboradores da pesquisa. Assim, o objetivo central dessa pesquisa foi investigar desafios e possibilidades do uso de tecnologias digitais no ensino de Matemática na visão de professores/as de escolas do campo.

O texto está organizado em mais quatro seções. Na próxima seção apresentamos reflexões teóricas sobre a presença/ausência de tecnologias digitais na realidade da Educação do Campo. Em seguida o foco está em descrever a metodologia e os instrumentos utilizados para a compreensão do fenômeno estudado. Depois de apresentar reflexões teóricas e os caminhos metodológicos, apresentamos os resultados da pesquisa, ressaltando elementos que problematizem os objetivos apresentados neste estudo.

saberes a serem ensinados, os espaços e tempos de aprendizagem, a formação docente e as práticas pedagógicas. 
Continuamos apresentando algumas considerações finais do texto e, por fim, as referências utilizadas são listadas.

\section{Educação do Campo e Tecnologias Digitais}

A Educação do Campo é um movimento fruto de lutas territoriais entre campesinato e agronegócio, na disputa pela terra e pela reforma agrária. A proposta da Educação do Campo está pautada como uma epistemologia que auxilie no desenvolvimento do campo, no sentido da transformação das realidades e na tomada do campo como lugar de produção de conhecimentos.

Neste sentido, Fernandes e Molina (2004, p. 9) afirmam que:

Por meio da Educação acontece o processo de construção do conhecimento, da pesquisa necessária para a proposição de projetos de desenvolvimento. Produzir seu espaço significa construir o seu próprio pensamento. E isso só é possível com uma educação voltada para os seus interesses, suas necessidades, suas identidades.

Assim, é possível pensar a educação voltada aos povos do campo e da floresta protagonizados pelos próprios sujeitos, visando o desenvolvimento dos seus espaços e na valorização dos seus modos de vida. Fernandes e Molina (2004, p. 10) são enfáticos ao conceberem que "A Educação do Campo pensa o campo e sua gente, seu modo de vida, de organização do trabalho e do espaço geográfico, de sua organização política e de suas identidades culturais, suas festas e seus conflitos".

Com a discussão que estamos traçando neste artigo, quando nos referimos às tecnologias na Educação recorremos a Masetto (2000, p. 152), ao afirmar que:

Por novas tecnologias em educação, estamos entendendo o uso da informática, do computador, da internet, do CD-ROM, da hipermídia, da multimídia, de ferramentas para educação a distância - como chats, grupos ou listas de discussão, correio eletrônico etc. e de outros recursos de linguagens digitais de que atualmente dispomos e que podem colaborar significativamente para tornar o processo de educação mais eficiente e mais eficaz.

O autor destaca diversas formas de possibilidades das novas tecnologias no contexto educativo, para ele o uso desses recursos pode contribuir significativamente para os processos de ensino e aprendizagem, mas destacamos que outras tecnologias foram por muito tempo utilizadas no processo de ensino de Matemática, como lápis e papel, régua e compasso, calculadoras. Masetto (2000) corrobora por apresentar as novas tecnologias educacionais promovem eficiência e eficácia para a educação. 
Destarte, embora as tecnologias digitais sejam fundantes no processo de modernidade, estão inseridas num cenário de disputas e estruturas de poder, pois além de prometer criatividade e inovação, como novidades nos nossos modos de interação e convivência, ainda não são acessíveis a todos, como destacado por Munarim (2014). É fato que muitas são as dicotomias entre o campo e a cidade, não como comparativo, mas para trazer ao debate que há direcionamentos diferentes das políticas públicas no que tange as estruturas e serviços para esses dois espaços e as relações que neles e entre eles estão estabelecidas.

Assim, com o surgimento e evolução dos recursos tecnológicos, outras formas de ver o contexto educacional passaram a ser discutidas e praticadas. Dessa forma, não podemos falar da escola que temos hoje nos moldes de décadas atrás, pois se hoje a sociedade é outra, as relações que emergem no contexto escolar também são outras. Neste viés, Lévy (2000, p. 8) concebe que a escola:

...é uma instituição que há cinco mil anos se baseia no falar/ditar do mestre, na escrita manuscrita do aluno e, há quatro séculos, em um uso moderado da impressão. Uma... verdadeira integração da informática supõe, portanto o abandono de um hábito antropológico mais que milenar o que não pode ser feito em alguns anos.

Com o avanço tecnológico vivenciado pela sociedade nas últimas décadas, as tecnologias passaram a adentrar o ambiente educativo, portanto, não podemos mais pensar em uma escola desvinculada dessa realidade. Sobremaneira, as tecnologias passaram a integrar comunidades rurais, tanto no uso nas relações sociais, quanto nas aplicabilidades aos processos produtivos do campo, pois:

A escola do campo deverá, portanto, representar para os povos do campo a possibilidade de construir uma vida digna e mais humana, respeitosa de suas tradições e modo de vida. $\mathrm{E}$ a introdução do acesso real a tecnologia nas escolas rurais poderia, à primeira vista, vir a ser um elemento facilitador desse processo de construção de uma nova cosmologia, que os aproxime das novas realidades numa perspectiva de educação e conhecimento, e não de submissão e colonização. (Belusso \& Pontarolo, 2017, p. 5).

Desse modo, o currículo da escola do campo precisa articular os saberes e identidade dos deferentes povos, ao passo que possibilite que prepare os estudantes para as necessidades vividas, mediando a construção de estratégias para viver com dignidade no campo a partir dos seus próprios modos de trabalho e produção.

Munarim (2014) reflete que para debater sobre o papel das tecnologias digitais nas escolas do campo, precisa-se de conhecer e legitimar as reivindicações dos sujeitos atendidos por essa proposta, e também tratar do conhecimento acumulado sobre o papel do 
uso de tecnologias na educação, embora essas abordagens ainda sejam incipientes nas escolas campesinas.

Maltempi (2008) ressalta que o uso das tecnologias nos diferentes níveis de ensino é necessário e oportuno, chamando atenção para não se perder de vista o ensino dos conteúdos matemáticos. Ressalta que:

...tanto a prática pedagógica quanto a matemática se modificam quando novas tecnologias tomam parte do ambiente de ensino e aprendizagem. Diante disso, professores e comunidade escolar têm dois caminhos possíveis: ignorar as tecnologias proibindo seu uso pelos alunos em sala de aula ou iniciar um processo de aprendizagem de modo a incorporar as tecnologias ao ambiente escolar. A primeira opção está cada vez mais difícil, devido ao caráter ubíquo que as tecnologias estão assumindo, e indesejável, dada a valorização que as tecnologias têm em nossa sociedade $\mathrm{e}$ as possibilidades proporcionadas pelas mesmas. A segunda opção representa um desafio a todo o sistema de ensino e de formação docente... (Maltempi, 2008, p. 62).

Para Maltempi (2008) a inserção de tecnologias em sala de aula é corroborada por duas demandas: uma diz respeito a necessidade imposta pela sociedade; outra está relacionada a ampliação das possibilidades de ensinar e aprender. Corrobora Alves (2011) ao desenvolver um estudo com estudantes do ensino fundamental de uma escola rural do município de Caruaru-PE, cujo foco foi a interpretação de gráficos por meio do uso de um software computacional, a autora verificou que os estudantes não apresentaram dificuldades no manuseio do computador e houve significativa interação na interpretação de gráficos.

Fraiha-Martins (2014) desenvolveu uma pesquisa sobre a significação do ensino de Ciências e Matemática na formação de professores para os primeiros anos de escolarização. A autora concebe que as experiências formativas com uso de tecnologias digitais corroboram para a promoção de processos de letramento científico-digital tendo em vista a elaboração de práticas pedagógicas diferenciadas de ensino. A pesquisa propõe um design de formação com ações formativas fundamentais aos processos de letramentos no século XXI: “i) Ensino com pesquisa em aula; ii) Integração de conhecimentos específicos inerentes aos anos iniciais; iii) Parceria(s) na docência; iv) Recursividade e retroalimentação da comunicação em aula" (Fraiha-Martins, 2014, p. 8). Ainda corrobora que:

É desejável permitir espaços para o futuro professor experimentar diversas tecnologias digitais em diversas propostas pedagógicas, contemplando diversos componentes curriculares. E tempos que possam respeitar o ritmo de cada licenciando no processo de aquisição de um estado ou condição de autoria docente que envolva o uso de tecnologias 
digitais em processos de ensino, passando a constituir sua formação básica para a docência (Fraiha-Martins, 2014, p. 176).

Com efeito, ratifica-se que a incorporação de tecnologias digitais na formação de professores de Matemática seja uma possibilidade para a prática docente neste cenário, propiciando o ensino dos conteúdos matemáticos e os movimentos pedagógicos oportunizados em aula.

\section{Procedimentos Metodológicos}

A realização dessa pesquisa partiu da abordagem qualitativa, pois levou em consideração a visão de professores do campo sobre o uso de tecnologias digitais no ensino de Matemática. A abordagem metodológica desta pesquisa, conforme Lüdke e André (1986), "tem o ambiente natural como sua fonte direta de dados e o pesquisador como seu principal instrumento" (p. 11); "Os dados coletados são predominantemente descritivos" (p. 12), pois foi feito transcrição das respostas aos questionários e observações produzidas durante as aulas; "A preocupação com o processo é muito maior do que com o produto" (p. 12), já que analisamos as interações dos estudantes com o uso das tecnologias digitais e suas reflexões sobre o seu uso nas escolas do campo; e verificamos os pontos de vista dos participantes da pesquisa sobre as questões que lhes foram apresentadas.

Como técnica de construção de dados utilizamos o questionário, pois é "um instrumento de coleta de dados, constituído por uma série ordenada de perguntas, que devem ser respondidas por escrito e sem a presença do entrevistador" (Marconi \& Lakatos, 2003, p. 201).

Participaram deste estudo oito licenciandos do curso de Licenciatura em Educação do Campo - Ênfase em Matemática, da Universidade Federal do Sul e Sudeste do Pará (Unifesspa), em Marabá (Pará, Brasil) durante o desenvolvimento da disciplina Informática no Ensino da Matemática, na etapa de janeiro/fevereiro de 2016. Todavia, um dos estudantes não participou de um dos momentos da pesquisa - portanto, na próxima seção, há análise de questionários com sete e com oito licenciandos.

A referida disciplina possui carga horária de 60 horas, a qual foi realizada durante o período de 27 de janeiro a 04 de fevereiro de 2016. Importante destacar que atuamos como professor formador do referido componente curricular, portanto, esta pesquisa foi desenvolvida durante o exercício da nossa prática docente como formador de professores que ensinam/ensinarão Matemática nas escolas do campo. 
A ementa da disciplina abrange:

Análise e discussão do papel da informática, e das novas tecnologias na Educação Matemática. O computador como recurso tecnológico no processo de ensinoaprendizagem da Matemática. Aulas práticas de softwares matemáticos. O LaTeX. (Unifesspa, 2014, p. 112).

Dessa forma, planejamos a disciplina com intuito de que os licenciandos pudessem apreender possibilidades para o uso das tecnologias digitais no ensino e aprendizagem de Matemática. Assim, os conteúdos da disciplina foram: Tecnologias da Informação e Comunicação na Educação; Tendências tecnológicas na Educação Brasileira; Informática e Educação Matemática; Tecnologias no Ensino de Matemática no contexto da Educação do Campo; Uso da web como recurso didático; WebQuest no Ensino de Matemática; Exploração de softwares como proposta didática para o ensino de matemática no Ensino Básico.

Durante a disciplina buscamos promover a formação docente para o uso de Tecnologias da Informação e Comunicação na Educação Matemática, subsidiando a utilização do computador, de softwares e da internet no ensino e aprendizagem de conteúdos matemáticos em contextos da Educação do Campo.

A disciplina teve caráter teórico-prático sobre o uso da informática e outras tecnologias na Educação Matemática. Assim, as aulas teóricas foram ministradas de forma expositiva, com uso de Data Show, bem como por meio de leitura de textos com finalidade de subsidiar as discussões teóricas sobre o papel das novas tecnologias na Educação Matemática. As aulas práticas compreenderam a exploração do computador como recurso didático para a Educação Matemática, bem como análise de WebQuests como recurso metodológico para os professores que ensinam/ensinarão conteúdos matemáticos nas escolas do campo. Nesse momento, foram apresentados softwares para o ensino e aprendizagem de conteúdos matemáticos, por meio de oficina sobre o uso do GeoGebra e Linguagem Logo, mostrando suas aplicações em diferentes conteúdos matemáticos.

\section{Desafios e Possibilidades do Uso das Tecnologias Digitais no Ensino de Matemática: Visão de um Grupo de Professores do Campo}

No primeiro dia de aula, solicitamos que os licenciandos respondessem a um questionário que tinha como propósito sondar os conhecimentos sobre o uso do computador e internet, bem como as opiniões sobre a importância do uso de recursos 
tecnológicos nas escolas do campo. Assim, sete dos licenciandos responderam ao questionário, tendo em vista que um deles não estava presente neste dia.

A primeira pergunta foi: "Você possui computador em casa?" Apenas uma $(14,3 \%)$ licencianda respondeu "Não", já os outros seis $(85,7 \%)$ afirmaram que possuem computador em suas residências. Em relação à pergunta: "Se sim, tem acesso à internet?", do universo desses seis licenciandos que tinham computador, quatro $(66,7 \%)$ informaram que possuíam acesso à internet em seus computadores pessoais, e apenas dois $(33,3 \%)$ não possuíam acesso à internet em suas casas.

Belusso e Pontarolo (2017, p. 2) apontam que:

A Internet como ator envolvido na compreensão dos fluxos de informação, de conhecimento e de poder que percorrem os territórios camponeses, pode vir a expandir a consciência dos direitos de elaboração de políticas públicas de inclusão e geração de bem estar, que vão do acesso a serviços públicos de saúde e educação à organização para o desenvolvimento no contexto local e regional.

Neste contexto, o acesso à internet possibilita a interação dos sujeitos do campo com informações e conhecimentos que podem repercutir na tomada de decisões com relação aos seus territórios. Portanto, o uso da internet pelos colaboradores da pesquisa está situado no cenário de disputas e de relações de poder que vislumbra a ação e a prática emancipatória em suas realidades. Também solicitamos que informassem qual o nível de conhecimentos em softwares de manuseio do computador, conforme a tabela abaixo:

Tabela 1: Conhecimentos dos professores-cursistas sobre informática básica

\begin{tabular}{|l|l|l|l|l|}
\cline { 2 - 5 } \multicolumn{1}{c|}{} & \multicolumn{1}{c|}{ Nenhum } & \multicolumn{1}{c|}{ Básico } & Intermediário & \multicolumn{1}{c|}{ Avançado } \\
\hline Editor de texto (Word) & --- & $\begin{array}{l}6 \text { licenciandos } \\
85,7 \%\end{array}$ & $\begin{array}{l}1 \text { licenciando } \\
14,3 \%\end{array}$ & --- \\
\hline Editor de planilha (Excel) & $\begin{array}{l}1 \text { licenciando } \\
14,3 \%\end{array}$ & $\begin{array}{l}6 \text { licenciandos } \\
85,7 \%\end{array}$ & --- & --- \\
\hline Editor de apresentação (Power & $\begin{array}{l}1 \text { licenciando } \\
\text { Point) }\end{array}$ & $\begin{array}{l}5 \text { licenciandos } \\
71,4 \%\end{array}$ & 1 licenciando & --- \\
\hline Internet & $---3 \%$ & 7 licenciandos & --- & -- \\
& & $100 \%$ & & \\
\hline
\end{tabular}

Fonte: Pesquisa de Campo (2020)

De acordo com a Tabela 1, percebemos que os participantes da disciplina tinham conhecimento básico sobre as principais ferramentas de uso do computador. Dos entrevistados, cinco $(71,4 \%)$ informaram ter conhecimentos básicos nos cinco itens do questionário (Word; Excel; Power Point; Internet); apenas um (14,3\%) licenciando informou possuir conhecimentos intermediários em Word e Power Point, e básico em Excel e Internet; ao passo que uma $(14,3 \%)$ licencianda indicou ter conhecimento básico 
em Word e Internet, enquanto que não sabe manusear os programas Excel e Power Point, sendo que esta licencianda é a que não possuía computador em sua residência.

Além de querer saber sobre os conhecimentos tecnológicos dos cursistas da disciplina Informática no Ensino da Matemática, estávamos interessados em saber sobre o que pensavam acerca do uso do computador no contexto da Educação do Campo, conforme nos apresentam a seguir:

Licenciando 1: Muito importante, pois com o uso do computador com certeza irá ajudar bastante o professor, quanto aos próprios alunos.

Licenciando 2: É uma maneira prática de manter os alunos literalmente conectados à realidade e mais próximos da tecnologia que atrai tanto o interesse dos jovens de hoje.

Licenciando 3: Com o atual avanço tecnológico é uma questão de necessidade implementar o uso do computador no processo ensino/aprendizagem.

Licenciando 4: Melhora a qualidade de ensino, torna a aprendizagem mais significativa. Quando o educador possui competência para utilizar este recurso.

Licenciando 5: É bastante importante, pois na maioria das comunidades as crianças não tem acesso a um computador, e hoje em dia o computador é essencial.

Licenciando 6: $O$ uso do computador nas escolas é ótimo mas quando tem professores habilitados a desenvolver atividades diferentes para tornar uma aula diferenciada. É bom pelo fato de ter algum material para fonte de pesquisa.

Licenciando 7: É um recurso didático importante, auxilia em pesquisas, facilitando a integração dos educandos com conhecimentos globais. E habilidades em informática.

Conforme as falas dos professores em formação inicial, o uso do computador que os alunos tenham acesso à informações externas à comunidade em que vivem, assim como apresenta o Licenciando 2 ao dizer que o computador possibilita que os alunos fiquem mais próximos da realidade, compreendemos que o uso do termo "realidade" expressa os fatos/informações que circulam fora de suas comunidades, assim como também informa Licenciando 7 em sua fala. De acordo com o Licenciando 6 e o Licenciando 7, a pesquisa é uma forma de oportunizar conhecimentos aos alunos, se referindo a pesquisa em fontes na internet.

Nestes termos, Belusso \& Pontarolo (2017, p. 6) destaque que:

...o acesso às tecnologias de informação podem ampliar ainda mais as redes territoriais desses estudantes na integração entre o rural e o urbano. Na sociedade da tecnologia torna-se um direito o acesso a informatização, a inclusão digital e as inúmeras possibilidades que se abrem com o acesso à rede mundial de computadores.

Embora nem todas as comunidades e escolas do campo tenham acessos aos computadores, como informa o Licenciando 5, cabe ressaltar que o uso de celulares é um meio de comunicação e acesso ao conhecimento presente nos territórios camponeses. É 
salutar que a informatização e a inclusão digital sejam uma realidade nas comunidades rurais, haja vista a rápida difusão dos meios tecnológicos na atualidade.

Outro ponto em destaque que requer atenção é o fato da qualificação docente para o uso pedagógico de tecnologias digitais no contexto da Educação do Campo, assim como nos apresentam o Licenciando 4 e o Licenciando 6, ao manifestarem que o computador contribui com o processo de ensino e aprendizagem "Quando o educador possui competência para utilizar este recurso” (Licenciando 4), uma vez que torna-se importante "ter professores habilitados a desenvolver atividades diferentes para tornar uma aula diferenciada” (Licenciando 6). Para Munarim (2007, p. 92-93):

A formação dos professores para o "uso" das tecnologias não deve se resumir apenas ao seu uso em sala de aula, mas também a momentos de reflexão em que eles possam conhecer, compreender e problematizar junto aos estudantes as dimensões políticas e econômicas que estão em jogo na produção dessas tecnologias. Daí a importância de que professores e estudantes saibam buscar informações, participem, produzam conteúdos próprios, planejem ações, incluam essas ferramentas digitais no cotidiano das escolas como mais um espaço de criação e expressão delas e dos sujeitos que com elas interagem. Que crianças, jovens, pais e professores possam utilizar essas tecnologias como um importante instrumento para suas buscas, suas lutas e seus questionamentos.

Portanto, a qualificação de professores para o uso de tecnologias digitais nas escolas do campo, precisa de momentos de reflexão sobre a sua inserção nas aulas de Matemática, e como pode contribuir para os enfrentamentos e lutas da comunidade. Durante o desenvolvimento da disciplina, lançamos o seguinte questionamento: "Qual a sua opinião sobre a inserção das tecnologias digitais como recurso pedagógico no ensino e aprendizagem de conteúdos matemáticos em escolas do campo? "No qual os licenciados responderam:

Licenciando 1: Acredito que, se todas as escolas do campo tivessem essa ferramenta, além de melhorar o ensino também ajudaria os professores e facilitaria no seu trabalho.

Licenciando 2: Desde que seja ministrada com responsabilidade é um projeto bastante produtivo, pois já houve em minha convivência tentativas que não deram certo, por falta de preparação dos instrutores, porém com orientação adequada penso que seja uma excelente maneira de desenvolver os conhecimentos matemáticos.

Licenciando 3: $O$ uso das tecnologias da informação como recurso pedagógico torna o ensino muito mais dinâmico, uma vez que podem ser explorados softwares e jogos pedagógicos.

Licenciando 4: De modo geral tais tecnologias quando utilizadas para tais fins podem auxiliar no processo de produção do conhecimento. Nas escolas do campo isso se torna fundamental uma vez que o campo não pode ser mais visto como lugar de atraso. Ainda, com o auxílio aos produtores nas melhorias de suas produções.

Licenciando 5: É uma inserção importante, pois por ser uma tecnologia importante, chama bastante atenção dos alunos, além de deixá-los mais atentos com o mundo.

Licenciando 6: Apesar da disciplina de Matemática ser vista como um bicho de sete cabeças, na concepção dos alunos, a minha opinião para inserção de tecnologias digitais 
como um recurso para o ensino e aprendizagem dos conteúdos de Matemática é muito boa, pelo fato de hoje a tecnologia ser acessada por todos, assim mostrando aos alunos que a Matemática não é nada disso que eles pensam, mas sim algo que pode ser prazeroso a se aprender. E mais, mostrar que o acesso a internet não só pode ser usada como rede social, mas como algo que você pode aprender e ensinar.

Licenciando 7: A escola deve auxiliar o educando no desenvolvimento das habilidades que ajude no bom desenvolvimento de sua vida social, assim, para a sociedade do século XXI, as tecnologias são indispensáveis. A escola do campo deve...

De acordo com a resposta do Licenciando 1, nem todas as escolas do campo possuem Laboratório de Informática, o que pode ser um entrave ao processo de ensino e aprendizagem, uma vez que ela reconhece que o uso de tecnologias digitais contribui com a prática dos professores. O Licenciando 2 diz que o professor deve ter o gerenciamento dos recursos tecnológicos como ferramenta de ensino, e assim, terá resultados positivos. Este cursista diz que teve algumas experiências mal sucedidas com a utilização de tecnologias no processo educacional, devido a falta de preparação dos instrutores. Todavia, o processo de ensino e aprendizagem de Matemática deve ser realizado pelo próprio professor, pois é ele quem tem o conhecimento do conteúdo e o conhecimento pedagógico do conteúdo, dessa forma, se o professor souber fazer uso das novas tecnologias poderá encaminhar o exercício docente mediado por elas.

Nas visões do Licenciando 3 e do Licenciando 4, as tecnologias digitais podem melhorar o ensino e proporcionar a aquisição de conhecimentos. Ressaltamos a fala do Licenciando 4 ao dizer que "Nas escolas do campo isso se torna fundamental uma vez que o campo não pode ser mais visto como lugar de atraso", pois por muito tempo o campo foi visto como lugar sem desenvolvimento e atrasado, mas essa visão começou a mudar, tendo em vista que os modos de vida sejam valorizados pela escola e a inserção de tecnologias digitais no ensino proporciona que os próprios alunos adquiram conhecimentos para além dos que são produzidos na comunidade, contribuindo com o fortalecimento do lugar, pois como o Licenciando 6 afirma que as tecnologias (como celulares e computadores) são acessadas por todos e isso pode contribuir para que a visão negativa que a Matemática possui seja transformada.

Fernandes e Molina (2004) destacam que o conceito de educação rural é associado à uma educação sem qualidade, precária e com poucos recursos, uma vez que o espaço rural era visto como arcaico e atrasado. Todavia, com o movimento Por uma Educação do Campo, passa a ser visto como lugar de produção de conhecimentos, como espaço de luta e resistência pelo direito de viver na terra, no sentido de garantir modos de vida que levem em conta o trabalho, a cultura e as relações sociais oriundos do campo, assim, "Esta 
neoconcepção educacional não está sendo construída para os trabalhadores rurais, mas por eles, com eles, camponeses" (Fernandes \& Molina, 2004, p. 9).

Tendo foco nas possibilidades do uso do computador e da internet ao processo de ensino e aprendizagem de Matemática, consideramos importante apresentar a ferramenta de ensino WebQuest. Embora entendamos que nem todas as escolas do campo tenham Laboratório de Informática e acesso à internet, nossas expectativas estavam em oportunizar aos licenciandos o conhecimento deste recurso didático, apresentando sua metodologia e discutindo sobre as limitações e possibilidades para as aulas de Matemática nas escolas do campo. Dentre as reflexões que emergiram durante as aulas, sugerimos a incorporação de WebQuest nas aulas de Matemática em escolas do campo de forma off-line ou apresentação de slide, mas seguindo a metodologia dessa ferramenta.

Devido à carga-horária da disciplina e o formato do curso ser intensivo (aulas nos turnos matutino e vespertino), propomos uma atividade de análise de WebQuests disponibilizadas na internet. Assim, os alunos foram organizados em quatro duplas com o objetivo de pesquisar e analisar os componentes que orientam as WebQuests, a saber: introdução; tarefa; processo; recursos; avaliação; conclusão.

As WebQuests escolhidas e analisadas pelas duplas foram: Há Matemática em Odivelas? ${ }^{2}$, pelos Licenciando 7 e Licenciando 3; Multiplicando ${ }^{3}$, pelos Licenciando 2 e Licenciando 4; a WebQuest Material Dourado ${ }^{4}$ foi analisada pelas duplas formadas por: Licenciando 1 e Licenciando 5; Licenciando 6 e Licenciando 8.

O interesse da análise que os licenciandos fizeram sobre o uso da WebQuest no ensino de Matemática para estudantes do campo estava em ressaltar as possibilidades e limitações nos contextos da Educação do Campo, ainda sugerimos que apontassem sugestões para que cada WebQuest ficasse mais próxima da realidade do campo, uma vez que elas não foram produzidas para este contexto educacional. De acordo com a análise dos educandos, ressaltamos os seguintes excertos:

Licenciando 3 e Licenciando 7: A proposta é interessante, dialogando com a proposta pensada para a educação do campo, trabalhar a partir das realidades dos sujeitos,

2 http://webquests.edufor.pt/webquest/soporte_horizontal_w.php?id_actividad=1758\&id_pagina=1. Acesso em: jul. 2017.

http://www.projectos.esffl.pt/phpwebquest/webquest/soporte_horizontal_w.php?id_actividad=496\&id_pagin $\underline{\mathrm{a}=1 .}$. Acesso em: jul. 2017.

http://www.projectos.esffl.pt/phpwebquest/webquest/soporte tabbed_w.php?id_actividad=619\&id_pagina=1 . Acesso em: jul. 2017. 
utilizando a pesquisa como princípio educativo, porém algumas adaptações considerando as localidades as quais estamos presentes, seriam necessárias, devido ao pouco acesso à internet, e a realidade social encontrada no campo. Já sabendo que esta atividade foi pensada para um contexto urbano.

Licenciando 2 e Licenciando 4: A nosso ver, o jogo é ótimo pois desperta a criatividade do educando motivando-o a aprender cada vez mais. Assim, uma consideração que se faz relevante dentro do contexto da educação do campo, que seria inserir questões problemas em forma de textos simples para facilitar a leitura, assim durante o jogo o estudante pode não somente responder questões aleatórias, mas também entender em que ambiente estas questões estariam inseridas.

Licenciando 1 e Licenciando 5: A principal limitação é a questão de muitas zonas rurais não terem acesso à internet e muito menos ao laboratório de informática para a realização dessas atividades usando a webquest. Tentar relacionar esses cálculos a realidade dos alunos, muitos dos alunos da zona rural trabalham ajudando os pais nas tarefas desenvolvidas na produção, para eles esses cálculos são conhecidos, mas quando se trata da matemática escolar há um estranhamento, pois, os mesmos ainda não conseguem fazer essa relação. Exemplo: o cálculo de área e volume pode ser trabalhado na construção de uma horta.

Licenciando 6 e Licenciando 8: O material dourado é um recurso útil no ensino aprendizagem dos educandos do campo, uma vez que o real objetivo do material é fazer com que a criança aprende brincando e manuseando interagindo com materiais próprios do cotidiano desse sujeito. Esse material sendo confeccionado por objetos que estão presentes na realidade onde estes estão inseridos. Fazendo parte dessa produção eles irão se sentir auto-confiantes e ampliar cada vez mais que fazer uso desse material.

$\mathrm{Na}$ análise da WebQuest Há Matemática em Odivelas?, Licenciando 3 e Licenciando 7 disseram que torna-se importante trabalhar com a realidade dos sujeitos do campo a partir da ferramenta, onde a pesquisa seja basilar neste processo, porém seria necessárias algumas adaptações tendo em vista a diversidade das localidades do campo, como por exemplo a falta de internet. Licenciando 1 e Licenciando 5 também são enfáticos ao dizerem que a falta de acesso à internet e Laboratórios de Informática nas escolas das zonas rurais é um limitador para o uso de WebQuests. Neste aspecto, sugerimos aos licenciandos que a metodologia da WebQuest pudesse ser implementada por meio do Power Point, assim os alunos seguiriam os passos sem precisar estar conectados na internet, e as pesquisas poderiam ser feitas em livros ou na comunidade.

A WebQuest Multiplicando tinha como suporte um jogo de operações básicas. A dupla formada por Licenciando 2 e Licenciando 4, ao analisar essa WebQuest, expressaram que o professor pode elaborar problemas que valorize a cultura e os contextos campesinos.

Ao analisarem a WebQuest Material Dourado, Licenciando 1 e Licenciando 5 relataram que as operações matemáticas escolares podem ser relacionadas com os saberes matemáticos presentes nas atividades produtivas do campo. Em análise dessa mesma 
WebQuest, Licenciando 6 e Licenciando 8 contribuem dizendo que o Material Dourado pode ser confeccionado com materiais da realidade dos alunos.

Fraiha-Martins (2014) concebe que a utilização de WebQuest no Ensino proporciona o uso de atrativos que a Web oferece, o que incentiva os estudantes na construção de conhecimentos consistentes e significativos, visto que "a WebQuest por se constituir no ciberespaço, se insere em uma realidade tecnologicamente mediada da qual o aluno faz parte, capaz de tornar-se um ambiente motivacional para a aprendizagem" (p. 161).

Assim, novas experimentações pedagógicas com o uso de recursos tecnológicos, como as vivenciadas durante a disciplina, oportunizam aprendizagens para o uso de tecnologias no ensino de Matemática. A inserção das tecnologias digitais em Educação Matemática permeia contribuições pedagógicas, uma vez que promovem mudanças na sala de aula, já que professor e aluno como passam a ser sujeitos cooperativos e colaborativos. Destarte, o professor precisa de atualização tendo em vista que a evolução tecnológica acontece muito rápido.

\section{Considerações Finais}

Ao finalizar este estudo sobre o uso de tecnologias digitais no ensino e aprendizagem de Matemática na visão de professores de escolas campo, ressaltamos que o avanço tecnológico hoje é uma realidade presente no contexto do sistema educacional brasileiro, no entanto, saber se o público alvo, ou seja, professores, alunos e demais membros da comunidade escolar estão preparados para se fazerem elementos desta esfera da atualidade é uma questão que merece uma avaliação aprimorada.

A investigação realizada durante o desenvolvimento de uma disciplina sobre o uso da Informática no Ensino da Matemática, ressaltando o contexto da Educação do Campo, possibilitou analisar desafios e perspectivas do uso de tecnologias digitais no processo de ensino e aprendizagem de Matemática em escolas do campo, segundo os licenciandos em Educação do Campo que participaram do estudo. Observando que a utilização das novas tecnologias vem causando a reestruturação do método tradicional de ensino.

Com as reflexões expostas neste texto, concebemos que o uso de computadores está cada vez mais presente em nossa sociedade, assim pode permear as práticas pedagógicas de ensino de Matemática nas escolas do campo, pois são de trivial importância à 
aprendizagem. De maneira geral, a utilização de tecnologias digitais vivenciada foi considerada pelos licenciandos como sendo de fácil compreensão e assimilação. O uso de tecnologias digitais para uma aprendizagem significativa é muito relevante, por ser um recurso que busca a curiosidade do aluno, assim atraindo e estimulando-o para uma aprendizagem na sociedade contemporânea. Tendo boa recepção dos alunos nesta nova forma de aprendizagem num contexto atual e moderno, o uso de tecnologias digitais nos processos de ensino de Matemática em escolas do campo ainda é um assunto que deve ser estudado e refletido, portanto, muito ainda se tem que pesquisar, problematizar e divulgar.

Os desafios expressos referem que: os licenciandos possuem conhecimentos básicos em informática; a maioria dos sujeitos e comunidades não possuem acesso a computador e internet; a falta de formação docente e técnica implica em experiências não exitosas; faz-se necessário fazer adaptações para uso da metodologia Webquest, inserindo a realidade camponesa.

Quanto as possibilidades verificamos que as tecnologias digitais: ajudam estudantes e professores no processo de ensino e aprendizagem; são atrativos aos alunos; são fontes de pesquisa; tornam o ensino mais dinâmico; contribuem com o processo de produção de conhecimentos, inclusive auxiliando nas atividades produtivas do campo; informam que o campo não é lugar de atraso; motivam e chamam atenção dos alunos; expandem a percepção e uso dos recursos tecnológicos.

De acordo com os pontos de vista dos professores que participaram deste estudo, as tecnologias têm potencialidades para a prática pedagógica do professor que ensina Matemática, todavia ainda há precariedade quanto a disponibilização de recursos tecnológicos, isto porque a escola pública do campo passa por dificuldades e contrariedades pedagógicas. Portanto, é necessário investimentos e políticas públicas para o enfrentamento dos desafios políticos e pedagógicos que essas escolas, os professores, os alunos e os demais agentes escolares são submetidos.

Este estudo levou em conta reflexões dos sujeitos do campo como partícipes do projeto educativo de suas comunidades, portanto as questões que envolvem educação e tecnologias digitais não se deslocam das realidades vivenciadas. Portanto, cabe pensar em políticas públicas para o uso de tecnologias digitais na realidade camponesa e no que se refere ao ensino e aprendizagem de Matemática. Espera-se que esta pesquisa possa oportunizar momentos de conhecimentos e reflexões sobre as tecnologias digitais e seus 
desafios e possibilidades para a Educação Matemática em escolas dos territórios camponeses, no que tange a formação de sujeitos críticos de suas realidades.

\section{Referências}

Almeida, M. E. B. (2010, 07-10 de junho). Web Currículo, caminhos e narrativas. [Palestra]. II Seminário Web Currículo, São Paulo, Brasil.

Alves, I. M. P. (2011). A interpretação de gráficos em um ambiente computacional por alunos de uma escola rural do município de Caruaru-PE [Dissertação de Mestrado, Universidade Federal de Pernambuco]. https://repositorio.ufpe.br/handle/123456789/3687.

Belusso, A., \& Pontarolo, E. (2017, 13 e 15 de setembro de 2017). Uma reflexão sobre tecnologia digital nas escolas do campo como possibilidade para o desenvolvimento dos territórios camponeses. [Ponencia] VIII Seminário Internacional sobre Desenvolvimento Regional, Rio Grande do Sul, Brasil.

Fernandes, B. M., \& Molina, M. C. (2004). O campo da Educação do Campo. In Molina, M. C., \& Jesus, S. M. S. A. (Orgs.). Contribuições para a construção de um projeto de Educação do Campo. Brasília: Articulação Nacional Por uma Educação do Campo. 53-90. (Coleção por uma Educação do Campo, n. 5). Disponible en http://www2.fct.unesp.br/nera/publicacoes/ArtigoMonicaBernardoEC5.pdf. Consulta: 16/06/2019.

Fraiha-Martins, F. (2014). Significação do ensino de Ciências e Matemática em processos de letramento científico-digital [Tese de Doutorado, Universidade Federal do Pará]. http://repositorio.ufpa.br/jspui/handle/2011/8505.

Lévy, P. (2000). As tecnologias da inteligência: o futuro do pensamento na era da informática. 9. ed. Rio de Janeiro: 34.

Ludke, M., \& André, M. E. D. A. (1986). Pesquisa em educação: abordagens qualitativas. São Paulo: EPU. (Temas Básicos de Educação e Ensino)

Maltempi, M. V. (2008). Educação matemática e tecnologias digitais: reflexões sobre prática e formação docente. In Acta Scientiae, 10 (1), p. 59-63, jan./jun. 2008. http://www.periodicos.ulbra.br/index.php/acta/article/viewFile/78/70. Consulta: 26/07/2020.

Marconi, M. A., \& Lakatos, E. M. (2003). Fundamentos de metodologia científica. 5. ed. São Paulo: Atlas.

Masetto, M. T. (2000). Mediação pedagógica e o uso da tecnologia. In Moran, J. M., Masetto, M. T., \& Behrens, M. A. (Coord). Novas tecnologias e mediação pedagógica. 12. ed. Campinas: Papirus.

Munarim, I. (2014). As tecnologias digitais nas escolas do campo: contextos, desafios e possibilidades [Tese de Doutorado, Universidade Federal de Santa Catarina]. RdDiPE

Unifesspa. (2014). Projeto Pedagógico do Curso do Licenciatura em Educação do Campo. Universidade Federal do Sul e Sudeste do Pará, Pará. 
José Sávio Bicho

Doutor em Educação em Ciências e Matemática pela Rede Amazônica de Educação em Ciências e Matemática (REAMEC/UFMT/UFPA/UEA). Professor Adjunto da Universidade Federal do Sul e Sudeste do Pará (UNIFESSPA). Editor da RdDiPE:

Revista Diálogos e Perspectivas em Educação. Membro do GT05 - História da Matemática e Cultura da Sociedade Brasileira de Educação Matemática (SBEM) e da Red Internacional de Etnomatemática. E-mail: saviobicho@yahoo.com.br 